\title{
0450 THE EFFECT OF A CELEBRITY DEATH ON CHILDREN'S INJURY-RELATED EMERGENCY DEPARTMENT VISITS
}

G Keays*, I B Pless Correspondence: The Montreal Children's Hospital, McGill University Health Centre, 2300 Tupper St., Montreal, OC H3H 1P3, Canada

\subsection{6/ip.2010.029215.450}

Background Following a skiing-related head injury death of the actor Natasha Richardson, we noted a marked increase in injury-related visits to the Emergency Department (ED) of the Montreal Children's Hospital (MCH). We assumed these visits were driven by media coverage, which would be greater in Quebec than elsewhere in Canada.

Methods Using data from the Canadian Hospitals Injury Reporting and Prevention Program (CHIRPP), we compared visits to the $\mathrm{MCH}-\mathrm{ED}$ for 10 weeks beginning in March. We also compared visits for the event week with the averages for the same week in the preceding 16 years. We noted the percent of MCH-ED visits that were for head injuries. Finally, we examined the same 10-week patterns for children's hospitals in Toronto, Calgary and Vancouver.

Results We found a $60 \%$ increase at the $\mathrm{MCH}$ for the event week compared with the first week of March and $66 \%$ increase compared to the 16-year average. We noted that for the event week $43.7 \%$ of injury visits were for head injuries compared with $28.8 \%$ (16-years average). There was, however, no change in ratio of severe head injuries. The increase in Toronto, Calgary and Vancouver was 24\%,23\% and 22\% respectively over the first week of March.

Interpretation These data suggest that the media coverage of this celebrity death which involved a failure to seek medical attention, generated anxiety among parents, prompting them to bring children to the ED who might not otherwise have sought medical care. 